\title{
Enacting Informal Science Learning: exploring the battle for informal learning
}

Informal Science Learning (ISL) is a policy narrative of interest in the UK and abroad. This paper explores how a group of English secondary school science teachers, enacted ISL science clubs through employing the Periodic Table of Videos (PTOV). It examines how these teachers 'battled' to enact ISL policy in performative (Lyotard, 1979) conditions at the micro-scale, and how this battle reflected macro-scale epistemological and political considerations. Data from the study suggests that for some, ISL was low-stakes as it was seen to have negligible impact upon performance data. As a result, there was some resistance toward enacting ISL and conflict between the formal and informal curriculum processes. Nonetheless, analysis indicates that the informants highly valued ISL despite the requirement for them to justify it over more formal and 'effective' approaches to learning science.

Keywords: performativity; informal science learning; policy; enactment; conflict

\section{Introduction}

Science education has been a high-level policy narrative in the United Kingdom and internationally. Although less high profile, Informal Science Learning (ISL) has similarly been an area for policy discussion and wider debate. In the 1980's and 1990's, there was a significant amount of work conducted which examined ISL and (a) children's informal ideas, Black and Lucas (1993); (b) learning outside the classroom, Braund and Reiss (2004); (c) scientific literacy, Lucas (1983, 1991); (d) play in science museums, Lucas et al (1986), Falk and Dierking (1992); (e) zoo visits, Tunnicliffe et al (1997) and (f) interactive science centres, Wellington (1989, 1990). Despite the evidence base advocating ISL as a powerful leaning approach, enacting ISL policy in England has proved to be challenging (Wellcome Trust, 2012b, 2014). As the Wellcome Trust indicates (2012b), the two primary factors inhibiting teachers' enacting ISL are (1) lack of time and (2) lack of assessable outputs. 
The title of this paper focuses upon what one teacher described as her 'battle' to enact ${ }^{1}$ ISL in her school, a battle which was similarly recounted by other informants. These teachers described fundamental tensions between the demands of the formal curriculum, increasingly located in 'performativity' (Lyotard, 1979), and their attempts to enact ISL. From examining ISL policy enactments at the micro-scale, the paper suggests that they reflected some of the macro-scale epistemological and political considerations which structure education both in the schools in question and in current national and international neo-liberal educational models.

It is important to be clear at the outset - the formal science curriculum is clearly not solely a performative tool. To claim otherwise would blur the epistemic distinctions between the functions of the formal and informal curriculum. However, the discourses rehearsed by the participants in this study suggest that performativity had crept so far into the systems of their schools that it suppressed anything other than overtly exam-focused teaching.

English schools have been described as inhabiting a 'performative' environment (Ball, 2003; Lyotard, 1979). Performativity is the drive for, and analysis of, efficient production and the 'optimisation' (Lyotard, 1979, 11) of the relationship between what is input into a system, and the corresponding level of output. Performativity promotes regulatory mechanisms (Ball, 2003) such as the high stakes school inspections completed by the Office for Standards in Education, Children's Services and Skills (OfSTED).

Successive UK Governments have positioned science as a central indicator of school effectiveness. As a result, the number of A*-C GCSE grades attained by students in science form part of the data set used by inspectors to rank schools. Consequently, the

\footnotetext{
${ }^{1}$ Policy is not implemented but enacted - that is, teachers read policy in relation to their own context and enact it with consideration of this context (see Ball et al, 2012).
} 
performance of students in science GCSE examinations, and the use of this data in school inspection, are increasingly high stakes (Perryman et al, 2011).

The paper examined ISL in the setting of science clubs which took place in three English secondary schools called for the purpose of this paper Willow Hill, Valley and New College. The paper considers how teachers in these schools employed a pedagogical tool - the Periodic Table of Videos (PTOV) - to support their enactment of ISL and how the informants' enactment of ISL resulted in the development of a decentralised informal curriculum.

\section{Defining an ISL science club}

Science learning is overwhelmingly equated with the formal science curriculum (Black and Lucas, 1993). However, people learn science from different sources, in different ways and for a variety of different reasons and which contrast from individual to individual (Lucas et al, 1986). For some people - at certain times and for certain reasons - learning in the formal curriculum can contribute more than the informal (Wellington and Ireson, 2008). However, the opposite is also the case - at certain times and for certain reasons informal learning can contribute more than the formal (Schibeci, 1989).

The Wellcome Trust (2012a. 2012b) highlighted how physical location was important in delineating between the formal and informal learning. ISL can take place outside of the formal school curriculum such as in theatres, music festivals and mediated by tools such as television, video, games and the internet. ISL can also take place in the formal setting of schools, colleges, science centres and museums (Philips et al, 2007).

What delineates the formal and the informal is far more than just location, as there are some fundamental pedagogical and epistemological differences (Lucas, 1983). Formal learning is mediated by the curriculum, is compulsory, deliberate, highly structured and regularly assessed. Informal learning is voluntary, haphazard and un- 
assessed. Moreover, ISL can be both intentional and unintentional, accidental and deliberate.

There are, of course, advantages and disadvantages for both formal and informal learning (Stocklmayer et al, 2010). However, the distinctions between the two are not necessarily clear-cut (Lucas, 1983) and there can be tension between the two. As Wellington and Ireson (2008) indicate, although informal learning can support the formal science curriculum processes it can also conflict with them. From drawing on the literature, this paper defined ISL science clubs as sessions sharing the following characteristics:

- occurred before school, at breaks, lunchtimes, after school and during non-formal curriculum time

- not assessed

- did not follow a set curriculum

- non-compulsory

- open to all students attend

Sessions which focussed on the following were not considered to be ISL science clubs:

- examination preparation and technique

- $\quad$ course work catch up

- linked closely to examination topics

- sessions only offered to a specific cohort of students in targeted attainment bands

- compulsory

- had assessment an integral part 


\section{Periodic Table of Videos (PTOV)}

The project employed the Periodic Table of Videos (PTOV) as an ISL intervention and to support ISL in the participants' science clubs. The purpose of using PTOV was to give the informants the opportunity to use a tool which was based upon an informal approach to science learning (Poliakoff and Harran. 2008).

PTOV is a free social media web site and video resource exploring different facets of chemistry. On the PTOV site the periodic table consists of an interactive menu. To access a PTOV, the viewer can either select individual videos from the You Tube channel by name, or click on an element on the periodic table which is displayed on the website homepage. A video resource is then revealed which provides a discussion on the element or topic for the session. PTOV are either named by element or by broad topic such as 'road trips'. As of January 2015 the site contained over 500 videos which had been watched just under 50 million times globally and with the YouTube channel having over 350,000 subscribers. In all of the ISL science clubs in this project, students had the opportunity to:

- access the PTOV website

- 'play' with the PTOV during the ISL science club sessions

- navigate around the interactive period table

- investigate different elements through the PTOV videos

- report back what they had discovered form PTOV to the rest of the group

- have group discussion around findings from using the PTOV 


\section{Research methodology}

Data were generated from science teachers $(n=5)$ who worked in three different schools in the Midlands of England, and by a focus group of teachers $(n=3)$ from a further two schools. The British Educational Research Association (BERA, 2011) ethical framework was adopted to ensure anonymity and protection of the informants.

Reflexive interviewing was employed which acknowledged that interviewing is a social practice (Kvale and Brinkman, 2008). In reflexive interviewing, the interview is recognised as (a) laden with ethical issues (b) embedded in social and historic context (c) involves asymmetrical power relationships between interviewer and interviewee. These were important consideration, due to the sensitive nature of some of the conversations which took place.

So as to achieve a level of trustworthiness (Guba and Lincoln, 1994), Denzin's (1970) approach of method triangulation was employed. Interview data were supplemented by data generated through observations (Delamont, 1976), see Table 1, and from a focus group of $(n=3)$ teachers from two further schools. The schools identified in this paper formed part of a partnership network and invitation to contribute was advertised in science departments in the schools with informants self-selecting to participate.

\section{TABLE 1 HERE}

Table 1. Data generation sources

Only three of the key informants had used PTOV prior to their participation in the research. Of the focus group, one informant had previous experience of PTOV. Prior to proceeding with data generation, all informants were given a month to explore the PTOV website and to choose three PTOV they wanted to use (Table 2). 


\section{TABLE 2 HERE}

Table 2. PTOV selected by participants for them to use in their ISL science clubs

From drawing on grounded theory literature (Strauss \& Corbin, 1998; Charmaz, 2005), analysis consisted of coding and the identification of concepts and categories. Concepts related to discrete phenomena, with categories linking groups of these phenomena together (Table. 3). In grounded theory, the coding of data informs the data the researcher investigates, and the hypotheses which are developed (Glaser \& Strauss, 1967). Consequently, rather than coding being a distinct and singular stage it was a continuous part of the analytical process (Strauss \& Corbin, 1998). From this analysis five categories emerged, although due to space restrictions only the final two are focussed upon here:

- What is science education for

- ISL and the school climate

- ISL and formal requirements of success

- The pressure to perform

- Developing an ISL curriculum

\section{TABLE 3 HERE}

Table 3. ISL category and concepts 


\section{The pressure to perform}

There has been research examining the pressures teachers face in their work (see Troman, 2000). Troman's work paints a picture of high-stakes milestones in teachers work which lead to a high pressure environment. Data analysis highlighted the 'pressure to perform' category which reflected how heavily the informants felt directed in their everyday teaching practice and the degree to which pressures from performative tools such as inspection directed their work .

In each of the three schools there were tightly defined learning schemes, assessment points, intervention groups and streaming. Additionally, there were highprofile high-stakes inspection readiness procedures where teachers took part in 'mockstead' inspections (see...). When all of these elements of the informants' work were allied to the large amounts of marking and lesson preparation required, these teachers maintained that opportunities for ISL and new pedagogical approaches were few. Analysis of the data in the pressure to perform category suggested that despite these pressures:

- ISL helped students to engage with scientific models

- ISL helped students to reflect on science as a way of understanding the world

- ISL gave students the opportunity for experimentation

- ISL supported group work

\section{Engaging with scientific models}

The Cola Problem PTOV explores how soft drink manufactures in the USA had to change their recipes because small amounts of a chemical (methylimidazol) had been found in the drinks. The video uses three dimensional molecular models both of the chemical and of caramel - which is used as colouring in the drinks and was the chemical's source - to represent the molecules in the drinks. Megan used the Cola problem PTOV to stimulate 
her students understanding of how to model a physical representation of the caramel molecule:

\begin{abstract}
Megan used molymod ${ }^{2}$ kits to demonstrate building a caramel molecule and then asked her year seven students to do the same. She asked them to 'pull apart' the molecule and label the different atoms which made the molecule. She then asked her group to explore what would be the consequences for the manufactures of changing the colouring of the drinks. This generated a discussion about brand loyalty, the psychological impact upon customers of changing a products colour, and the possibility of competitors increasing their market share. (Observation field note)
\end{abstract}

In this instance, the students were given the opportunity to 'play' with molymod kits - none of the group had used them previously - in the same way as Jordan, one of the students, described as a "proper" scientist had done in the PTOV. The contextualisation of the learning as something both the students, and a 'proper' scientist, could do was central to the students' learning. Moreover, the discussion generated around the ethical and business considerations of the drink colouring was located in the 'real world' context of a drink all the students had tasted.

What emerged from the analysis of the Cola problem session, was that the students' learning could clearly be direct toward both an informal settings but also formal science examinations. The purpose of Megan's sessions was to stimulate her students' understanding of what 'proper' scientist did and highlighted that, at least in the smallscale example of using the moly-mod kits, her students could do the same thing. What was particularly powerful was how the students engaged with the task and were able to construct their own molecular models with confidence and accuracy after only a short time period.

\footnotetext{
${ }^{2}$ Molmod kits are used to build three-dimensional models for organic, inorganic chemistry, biochemistry and general science applications
} 
This ISL session was in stark contrast to what Megan described as the formulaic approach outlined in the school's Schemes of Work which suggested that students draw molecules from chemical formula. For Megan, absent in this approach was the vital contextualisation for her students of molecular modelling - contextualisation which was central in the cola-problem PTOV. In contrast to ISL, and due to the absence of contextualisation in the formal approach, Megan claimed that the abstract and decontextualised nature of molecular modelling prevalent in the formal approach to the topic remained just that for her students abstract, and at times, impenetrable.

\section{Science as a way of understanding the world}

Evident in the data was how ISL helped students to be what Claxton $(2007,132)$ called 'venturesome' in their learning. For example, Sahida used the Chemical Weapons PTOV to focus on the ethical dilemmas surrounding the science of nuclear weapons. After watching the video, the group was split into two and given the task of debating for, or against, the science which underpinned the development of nuclear weapons.

Of note in this instance was how the students engaged with debating and ethical argument which, as one of the students Stevie commented, was an important point:

What I found out was that if I have to argue about something then the facts are really important...it's like knowing the scientific facts is like having power which you can use. It's not like facts don't have a point...they do. (Observation field note)

A particularly interesting part of the session then followed. In answer to Stevie's comment, Sahida opened up a further debate which examined what was the importance of evidence in the scientific method. From the ensuing conversations, the students outlined how considering science as a means of developing evidence highlighted that 'facts' were more than just important for answering test questions. 
For Sahida, central to the session was that her students had the opportunity to experience how science could be used in 'real' life. This was an opportunity she rehearsed which was simply not possible within a formal setting due to the time pressures of the day-to-day curriculum. The group had a range of powerful opinions regarding nuclear weapons and the session illustrated the importance of exploring scientific ethical dilemmas through ISL.

\section{Opportunity for experimentation}

The informants suggested that practical work, and particularly investigations, had diminished due to increasing demands on curriculum time (see Dillon, 2008). Megan chose to address this through her ISL science club by using the Perfect Perfume PTOV. Megan had taken her group to the local shopping centre where the students explored the various perfumes on sale. They were asked to rank the aroma, packaging and advertising of the product and link this to the price, this was collated as data which the students took back with them to school. When they returned to the school laboratory:

...the students had access to a range of ingredients with which to design their own perfume. The level of accuracy they demonstrated with regard to measuring, cataloguing and designing experiments was particularly impressive. (Observation field note)

The transformation of the local shopping centre into an ISL venue was a significant part of the session. This process also drew parallels with what Tully and Lucas (1991) describe as the 'vicarious and direct' learning experiences which can result from 'direct interaction' with artefacts in a setting. Drawing together the students' learning from the video, their own field work and the approaches they used in the manufacture of their own fragrance was supported by an ISL experience. As Ishmael illustrated: 
Going to the shop and then back to school changed how I thought about the session. I learnt loads about the chemistry involved in making perfumes and I can see how something that I'm not particularly interested in as a product is really interesting from a chemistry viewpoint. (Observation field note)

\section{Group work}

What stood out in the data were how group work was a key component of ISL. Charlie's session exploring Quick Response (QR) codes, required his students to design their own periodic table using a QR code generator. Drawing on a model developed by the PTOV team, the students made their own video on an element and then produced a high resolution printable QR code which would link a Smartphone user to their video and the PTOV website.

Rakim made the point that in an ISL environment, group work is natural. Whilst he used group work regularly in his formal science classes, Rakim remarked that ISL lent itself to an almost organic forming and reforming of groups. He reported that in curriculum time where he carefully considered the groupings, but he was open to the students having a free choice as to groupings within the informal setting. This of course could be due to the students opting to come to the sessions and therefore more disposed to working in such ways. However, Rakim was adamant that there was an element of ISL which had re-orientated the students, and his own, approach toward group work.

\section{Developing an ISL curriculum}

There has been work which explores stakeholders' views upon the science curriculum (see Osborne and Collins, 2001). What was evident in the 'developing an ISL curriculum' category was that the informants rehearsed a tension between the formal and informal curriculum. There was a consensus amongst informants that the formal curriculum had become increasingly examination focussed rather than developing students' 
understanding of scientific processes (see Geelan et al, 2004).

The informants maintained that one of the consequences of an examination facing formal curriculum was that opportunities for students to explore scientific concepts, and crucially to get things wrong, were seldom. It was to address this limitation that the informants felt ISL gave them and their students' opportunity for a space to consider science through a different lens. Analysis of the data in this category suggested that:

- The informants described conflict between an ISL curriculum and the demands of the formal curriculum

\section{Curriculum conflict}

What was particularly evident in the data was the conflict between the ISL curriculum evident in science clubs and the formal day-to-day curriculum. In all of the informants' schools, science clubs tended to be formal with an overt focus on improving students' attainment. Megan outlined how she wanted to challenge this model:

I went to science club at school and they were great. They were about really exploring some of the stuff we did in lessons but somehow they were different. They were relaxed and informal...and I felt like a 'proper' scientist. That's what I want my science club to be like. (Megan - interview)

The data also suggested that ISL was used by informants as a means of circumnavigating the constraints imposed upon their teaching by the demands of what Charlie described as an "examination facing curriculum". Moreover, ISL supported the informants to explore parts of science education they did not have the time, or justification, to explore during curriculum time lessons.

Ben-Peretz (1990) outlined the 'encounter' between teachers and curriculum and how some teachers decide to re-orientate the relationship between what is indicated as to 
be taught and what they actually teach. This notion of curriculum re-orientation played out in the informants' experiences of ISL:

There's so much dictated about what we teach, and how and when we teach it, that doing something outside of all that is really refreshing. (Charlie - interview)

Like ISL, informants suggested that PTOV was also outside of the formal curriculum. The lack of claims that PTOV were a revision aid, or might improve attainment, was a major strength of the tool for the informants. This did however pose some challenges:

I feel like I have to justify using something like PTOV in terms of how it will improve attainment... (Rakim - interview)

Crucially, ISL appeared to be an attempt by the informants to wrestle some control of the curriculum. The tension between the demands of the formal curriculum and ISL was played out the conversation which forms the title of this paper. Megan described how her Head of Faculty had talked to her about ISL:

I've been told that science club has to become more focussed. I can't do the fun stuff anymore. It has to support the kids in their attainment... it has to become a science exam prep club. I'm not doing that. (Megan - interview)

Indeed, Megan reported that a member of her faculty described ISL as "watering down" the impact of formal science clubs upon the faculty's performance.

Despite the difficulties arising from the conflict between the formal and informal curriculum, the data suggested that students' excitement and interest in science was enhanced by ISL. For example, Harvey's group watched and then completed their own version of the Cheeseburger PTOV by using food available from the school's canteen. 
This video depicts how a cheeseburger decomposes when placed in hydrochloric acid as an example of the digestive process:

\footnotetext{
The students were given a choice of three PTOV to watch. When they decided on the Cheeseburger PTOV Harvey accessed the video via YouTube and played it to the group - much to their noisy disgust when they saw the burger decomposing! (Observation field note)
}

This example of science in the 'real-world' was particularly impactful. The students' vocal comments - and facial expressions of disgust when seeing such a popular meal choice transform into anything other than an appetising form - allied to their ability to equate the scientific process in play with their own lives evidenced the impact this particular ISL approach.

\section{Discussion}

From considering the informants' data there are a number of key issues which have emerged. Primary amongst these was that enacting ISL was not without serious challenges. There appeared to be entrenched resistance towards ISL by some teachers, seemingly founded on the fear that informal learning would negatively impact upon students' examination attainment. This resistance could of course be a consequence of teachers simply not wanting, or having the time, to run science clubs. Although this second suggestion seems to be plausible, the data leads to the former having to be seriously considered.

The performative discourse at play were so prevalent that the notion of informal learning was, to some teachers at least, difficult to assimilate with the high-stakes testing culture in which they worked. This is a crucial point. The resistance displayed did not appear to be toward science clubs per se, rather it was directed towards informal 
approaches to science learning. As Megan reported, for some of her colleagues informal simply meant unfocussed and unproductive.

What was also of interest, was how ISL met resistance from some students. Charlie rehearsed how some of his students were confused with his ISL approach to science club. For some of Charlie's students, science club was about preparation for examinations. The need to justify ISL in relation to performance demands resulted in a tension between how the informants interpreted ISL and their 'coal face' work. For all the informants, performative demands were the single largest hurdle to overcome in relation to embedding ISL into their day-to-day work.

The informants suggested that when freed from the formal curriculum pressures they and their students faced, ISL gave the opportunity to think and reflect. What was particularly impactful was that the teachers themselves appreciated this opportunity. For example, all of the informants reported that they had developed their own subject and pedagogical knowledge from engaging with the PTOVs. Of course it could be argued that the development of such knowledge could have been the result of engagement with any effective resource. However, the informants reported that it was engaging with ISL outside of the day-to-day pressures of their work which was central to this process.

Wrapped up in this freedom, was how ISL supported the opportunity for process as well as facts to be explored, and for both of these to be contextualised within the 'realworld'. For the informants there was an almost inevitable focussing of science learning upon what students needed for examinations. Whilst they all maintained examinations were important, this focus had negated the opportunity for students and teachers to explore science informally and contextually.

Central to the tension between ISL and performative demands, was the conflict between the formal and informal curriculum. This tension resonates with the work of 
Wellington and Ireson (2008), who highlight that informal learning can both support and conflict the formal science curriculum. It was this conflict which, in many ways, underpinned the challenges the informants faced in raising the profile of ISL. Ultimately, the conflict between the formal and informal curriculum had a significant impact upon how these teachers had to 'sell' ISL to their colleagues.

For the informants, ISL did support a vital part of re-orientating the formal curriculum though one crucial element - time. In the formal curriculum time was a constant pressure, with the need to 'cover' content and complete assessments the key driver. Without these pressures, ISL supported three key activities:

- time to get things wrong and learn from the process

- time to do new things

- time to contextualise science in the world

For the informants, giving students the opportunity to engage with science, and to possibly fail in the process, was fundamental to ISL. The formal curriculum was so highly directing that there was little or no time to review and reflect upon results which did not fit the expected pattern. Informants identified the process of discovery through exploring the unexpected as a cornerstone of science, and yet they maintained that discovery and failure were being increasingly marginalised. For these teachers, the formal curriculum just did not have time for students to engage with incorrect answers.

Similarly, ISL supported the opportunity for the informants to try new pedagogical methods. This was a particular strength of the PTOV, there were many instances where approaches towards science learning were modelled in ways which the teachers had not previously encountered. As such, ISL led to new ways of exploring topics for both teachers and students. 
ISL also gave the opportunity for students to be released from the pressure to produce results which fitted a mark scheme. This was an important point for both teachers and students. Being released from the requirement to produce 'the' answer meant that students could produce 'an' answer. Moreover, ISL supported the opportunity to consider the results the students had produced in terms of questions such as "does this seem likely"?

Finally, and vitally, ISL gave students the opportunity to contextualise science. The trip to the shopping centre's perfume counter was one example of such contextualisation. A central part of the ISL models employed by the informants was that science should not be divorced from the 'real-world'. Indeed, for these teachers their dayto-day work had lost sight of the notion that science was a way of understanding the world.

What strongly resonated with all the informants, was how they reported that they were increasingly asked to teach their students to remember and regurgitate facts rather than develop a deep understanding of the scientific world. For too many of their students, science was about "boring stuff" that they did not understand. Key to this lack of understanding was lack of context. For the teachers in this study, ISL was fundamentally about contextualising science in the world that their students recognised.

\section{Fighting the battle for informal science learning}

Considering how the teachers in this study enacted ISL at the micro-scale, reveals macroscale epistemological and political considerations. The informants' data has suggested that the neo-liberal and performative educational model outlined by authors such as Ball (2003), has fundamentally impacted on their work as science educators. Inevitably, these considerations also have significant consequences for ISL and informal learning per se. 
For the informants, science teaching had become inextricably linked with 'pressure cooker' (Perryman et al, 2011) performative measures. They also maintained that as a result informal learning was difficult, if not impossible, to enact. When keeping this context in mind, it appears that there are two headline findings:

- ISL had to be justified within performative contexts

- there was conflict between formal and informal science curriculum

From considering these headlines, it seems that the research reported here paints a sobering picture of these informants' attempts to enact ISL due to seemingly entrenched deficit models surrounding informal learning. Nevertheless, there is a positive side. Despite challenging circumstances, the key informants developed and enacted ISL approaches which they maintained enhanced learning, and indeed enjoyment, of science (see Osborne and Dillon, 2007). For the informants, ISL enabled them to locate their students' learning within an informal context not constrained by the demands of the formal curriculum and examinations. Vitally, the informants maintained that it was this ISL context which gave their students freedom to learn.

Ball et al $(2012,145)$ assert that 'performance...is perhaps the master discourse of schooling in the twenty-first century'. In the cases reported here, the 'embeddedness' of performance in schools appeared to undermine ISL enactment. Nonetheless, the informants' enacted models of ISL that they maintained worked in the contexts of their schools.

To conclude, it seems appropriate to reconsider the title of this paper which claimed that there was a 'battle' to enact ISL. From investigating the cases reported here, this was a battle the informants passionately felt worth fighting despite not being an easy 
course of action. Indeed, it could be argued that 'informal' learning was seen as unproductive, unfocused and unhelpful. Nonetheless, for these teachers fighting to enact ISL is their schools not only benefited their students, it also emphasised that learning science was fundamentally about understanding the world as much as attaining performative metrics.

\section{References}

Ball, S. 2003. The teacher's soul and the terrors of performativity. Journal of Education Policy 18:2, 215-228.

Ball, S., Maguire, M., \& Braun, A. 2012. How Schools Do Policy: Policy Enactments in Secondary Schools Abingdon: Routledge

Ben-Peretz, M. 1990. The Teacher-Curriculum Encounter. Freeing Teachers form the Tyranny of Texts. New York. State University of New York Press.

Black, P., and Lucas, A. (Eds). 1993. Children's Informal Ideas in Science. London. Routledge.

Braund. M., \& Reiss, M. (Eds). 2004. Learning Science outside the Classroom. Abingdon. Routledge. pp1-13

British Educational Research Association (BERA). 2011 Ethical guidelines for educational

research. http://content.yudu.com/Library/A1t9gr/BERAEthicalGuideline/resources/index .htm?referrerUrl=http\%25253A\%25252F\%25252Fwww.yudu.com\%25252Fite m\%25252Fdetails\%25252F375952\%25252FBERA-Ethical-Guidelines-2011 accessed July 2014

Charmaz, K. 2005. Grounded Theory in the 21st Century. In N. Denzin \& Y. Lincoln (Eds.), Handbook of Qualitative Research (3rd ed.). Thousand Oaks: Sage. 
Claxton, G. 2007. Expanding Young People's Capacity to Learn, British Journal of Educational Studies, 55:2, 115-134

Delamont, S. 1976. Beyond Flanders Fields: The Relationship of Subject Matter and Individuality to Classroom Style. In Explorations in Classroom Observation, M. Stubbs, and S. Delamont (Eds), 101-131. London: John Wiley and Sons.

Denzin, N. 1970. The Research Act in Sociology. Chicago: Aldine.

Dillon, J. 2008. A review of the Research on Practical Work in School Science. London: Kings Collage

Falk, J., and D. Dierking. 1992, The Museum Experience. Washington. Whalesback Books.

Geelan. R., H. Wildy. W. Louden and J, Wallace. 2004. Teaching for understanding and/or teaching for the examination in high school physics, International Journal of Science Education, 26:4, 447-462

Glaser, B., \& Strauss, A. 1967. The Discovery of Grounded Theory: Strategies for Qualitative Research. Chicago: Aldine.

Guba, E. and Lincoln, Y. 1994. Competing Paradigms in Qualitative Research. In Denzin, N., \& Lincoln, Y. (Eds.). (2005). The Sage Handbook of Qualitative Research (2nd ed.). London: Sage.

Kvale, S., and S. Brinkman. 2008. Interviews. Learning the Craft of Qualitative Research Interviewing. London: Sage

Lucas. A. 1983. Scientific Literacy and Informal Science Learning. Studies in Science Education, 10:1, 1-36

Lucas. A. 1991. 'Info-tainmnet' and informal Sources for Learning Science. International Journal of Science Education. 13:5, 495-504 
Lucas, A, McManus, P \& G. Thomas. 1986. Investigating learning from informal Sources: Listening to Conversations and Observing Play in Science Museums. European Journal of Science Education. 8:4, 341-352

Lyotard, J. 1979. The postmodern condition: A report on knowledge (G. Bennington and B. Massumi, Trans.). Manchester: Manchester University Press.

Osborne, J. and Collins, S., 2001. Pupils' views of the role and value of the science curriculum: a focus group study. International Journal of Science Education, 23(5), 441-467.

Osborne, J. and J. Dillon. 2007. Research on learning in Informal Contexts: Advancing the field? International Journal of Science Education, 29:12, 1441-1445

Perryman, J. S, Ball, M, Maguire and A, Braun. 2011. Life in the Pressure Cooker School League Tables and English and Mathematics Teachers' Responses to Accountability in a Results-Driven Era, British Journal of Educational Studies, 59:2, 179-195,

Philips, M., D, Finklestein and S. Wever-Freichs. 2007. School site to Museum Floor: How informal science institutions work with schools. International Journal of Science Education, 29:12, 1489-1507

Poliakoff, M., and B. Harran. 2008. YouTube in its element. Teaching Chemical Engineering. December 2008/January 2009.

Schibeci, R, 1989. Home and School Peer Group Influences on Student Attitudes and Achievement in Science. Science Education. 73:1 13-24

Stocklmayer, S., L. Rennie, and J. Gilbert. 2010. The roles of the formal and informal sectors in the provision of effective science education. Studies in Science Education, 46:1, 1-44. 
Strauss, A., and Corbin, J. 1998. Basics of Qualitative Research: Techniques and Procedures for Developing Grounded Theory. Thousand Oaks: Sage.

Troman, G. 2000. Teacher stress in the low-trust Society. British Journal of Sociology of Education 21:3, 331-353.

Tully, A., and Lucas. A. 1991. Interacting with a science museum exhibit: vicarious and direct experience and subsequent understanding. International Journal of Science Education. 13:5, 533-542

Tunnicliffe, S, Lucas, A and Osborne, J. 1997. School visits to zoos and museums: a missed educational opportunity? International Journal of Science Education 19:9, $1039-1056$

Wellcome Trust, 2012a. Review of informal science learning. London: Wellcome Trust

Wellcome Trust, 2012b, Analysing the UK science education community: The contribution of informal providers. London: Wellcome Trust

Wellcome Trust, 2014. Science learning+: Collaborative adventures in informal research and practice. $\quad$ http://www.wellcome.ac.uk/Funding/Publicengagement/Funding-schemes/Science-Learning/index.htm accessed July 2014

Wellington, J. 1989 Attitudes before Understanding: the Function of Interactive Centres in the National Science Curriculum, in Sharing Science, London: Nuffield Foundation, pp. 30-33.

Wellington, J. 1990. Formal and Informal learning in Science: the role of the Interactive Science Centres. Physics Education, 25:5, 247-252

Wellington, J., and Ireson, G, 2008. Science Learning, Science Teaching. London: Routledge. 